\title{
Air Quality Analyses for Photochemical Smog Associated with Atmospheric Aerosol Particles and Ozone Precursors Using CMAQ and CAMx Modeling Systems
}

\author{
Muhammad Ibrahim ${ }^{1,2}$ \\ ${ }^{1}$ Department of Environmental Management and Toxicology, Federal University Dutse, Nigeria \\ ${ }^{2}$ Department of Environmental Science and Engineering, Hohai University Nanjing, Jiangsu Province, P. R. China
}

\begin{abstract}
Pollution due to air quality deterioration is directly or indirectly connected to the phenomenon of biogeochemistry (i.e the scientific discipline that involves the study of the chemical, physical, geological, and biological processes and reactions that influence the composition of the natural environment) which in turn links to the human health. Human health and well-being, along with the well-being of animals, plants, and agricultural products, are solely dependent upon the quality of air we inhale. In response to the emission control threshold levels, prediction of how changes in emission levels could affect ambient air quality has been documented. The use of photochemical air quality models is becoming widely acceptable by various global regulatory agencies for the purpose of regulatory analyses and for the attainment exhibition by evaluating and assessing the effectiveness of control strategies. This review work tries to figure out the two most important and uncommon models namely; Comprehensive Air Quality Model with Extensions (CAMx) and Community Multiscale Air Quality (CMAQ) Modeling System. These modeling systems are used to predict, characterize, determine and simulate the photochemical air quality conditions. This paper gives a substantial detailed information of findings from related multidimensional studies carried out long ago and recently on photochemical smog analyses. Photochemical smog; causes and impacts on both the environment and livingbeing health were succinctly spelt out. Ozone formation and its different precursors; atmospheric aerosols; emission of biogenics as well as Ozone modeling phases were also discussed. The researcher still talks about the model formulations such as Zhang Model formulation; application and history of CMAQ and CAMx models respectively.
\end{abstract}

Keywords: Photochemical Smog, Atmospheric Aerosol Particles, Ozone Precursors, CMAQ and CAMx

\section{INTRODUCTION}

Pollution due to air quality deterioration is directly or indirectly connected to the phenomenon of biogeochemistry (i.e the scientific discipline that involves the study of the chemical, physical, geological, and biological processes and reactions that influence the composition of the natural environment) which in turn links to the human health. Human health and well-being, along with the well-being of animals, plants, and agricultural products, is solely dependent upon the quality of air we inhale (Sillman and Arbor, 2014). In response to the emission control threshold levels, prediction of how changes in emission levels could affect ambient air quality has been introduced (Leone and Seinfeld, 1984). Nowadays, the differences amongst various mechanisms would not be of any concern in as much as each of the mechanisms gives similar predictions over a range of atmospheric conditions. Conversely, much number of recent investigations have established that different mechanisms predict 
substantially different degrees of emission controls to achieve the same desired air quality under identical conditions (Jeffries et al., 1981; Whitten, 1981; Carter et al., 1982a; Dunker et al., 1984). The use of photochemical air quality models is becoming widely acceptable by various global regulatory agencies for the purpose of regulatory analysis and for the attainment exhibition by evaluating and assessing the effectiveness of control strategies.

This work tries to figure out the two most important and uncommon models used to predict, characterize, determine and simulate the photochemical air quality conditions. These photochemical models are large-scale air quality models that simulate the changes of pollutant concentrations in the atmosphere using a set of mathematical equations characterizing the physical and chemical processes in the atmosphere. Dry deposition is having a big deal of interest from today's researchers due to its effects on the environment; consequently, there have been significant efforts to measure or estimate dry deposition using a variety of techniques (Mohan, 2016). Photochemical grid models are intended to accurately depict the ways in which air pollution forms, accumulates, and dissipates by simulating the processes that are most essential in generating ozone pollution. These models have emission data from industrial sources, and many other mobile sources that emit chemicals which lead to the formation of ozone and simulate the atmospheric reactions that result in ozone formation. It is documented that photodissociation of many trace gaseous elements has been found to be the precursor for the initiation of most of the atmospheric chemical reactions (Shawn, Jonathan and Kenneth, 1997). The models are driven by meteorological models that are similar to those relied upon by weather forecasters because they can analyze the winds that carry pollutants to other areas around where the source is.

\section{PHOTOCHEMICAL SMOG}

Photochemical smog is described as a composition of primary and secondary pollutants. Primary pollutants, which include volatile organic compounds (VOCs), and Nitrogen oxides (NOx) are introduced into the atmosphere through vehicular emissions and industrial processes. Whereas secondary pollutants, like ozone $\left(\mathrm{O}_{3}\right)$, result from the reaction of primary pollutants with ultraviolet light. Photochemical smog is most common in those cities characterized with sunny and dry seasons and it has a variety of negative health impacts.

\subsection{Causes of Photochemical Smog}

This type of air pollution is formed through the reaction of solar radiation with airborne pollutants like Volatile Organic Compounds (VOCs), and Nitrogen oxides (NOx). These compounds, which are called primary pollutants, are often introduced into the atmosphere through automobile emissions and industrial processes as earlier said. Ultraviolet light can split nitrogen dioxide into nitric oxide and monatomic oxygen; this monatomic oxygen can then react with oxygen gas to form ozone. Products like ozone, aldehydes, and peroxyacetyl nitrates are called secondary pollutants. The mixture of these primary and secondary pollutants forms what is termed as photochemical smog.

\subsection{Ozone}

Ozone occurs naturally in the troposphere, predominantly as a result of downward mixing from the stratosphere. This downward mixing includes both direct transport of ozone and transport of NOx, which leads to photochemical formation of ozone in the troposphere. Ozone mixing ratios in the stratosphere (from approximately 20 - $60 \mathrm{~km}$ above ground level) are as high as 15000 parts per billion (ppb). This is higher than ozone concentrations at ground level, even in the most polluted regions, by a factor of 100. Approximately 95\% of the Earth's 
ozone is located in the stratosphere. Ozone in the troposphere is much lower and generally decreases from the top of the troposphere to ground level. The ozone that is transported downward from the stratosphere is removed through photochemical processes in the troposphere (which include both production and removal of ozone, but with removal rates exceeding production rates). Ozone is also removed through dry deposition at the Earth's surface. Removal of ozone in the troposphere happens on a timescale of approximately three months. In the absence of human activities, ozone concentrations would vary from $200 \mathrm{ppb}$ in the upper troposphere to $10-20 \mathrm{ppb}$ at ground level.

\subsection{Ozone Precursors ( $\mathrm{NOx}, \mathrm{CO}$, and Volatile Organics)}

Ozone in urban areas is produced from two major classes of precursors: $\mathrm{NOx}$, consisting of $\mathrm{NO}$ and $\mathrm{NO}_{2}$, and VOC. The ozone formation process is also closely associated with the hydroxyl radical $(\mathrm{OH})$. The process of ozone formation is initiated by the reaction of organics (usually primary hydrocarbons) with $\mathrm{OH}$. The subsequent reaction sequence involves $\mathrm{NOx}$ and results simultaneously in the production of ozone, oxidation of organics to $\mathrm{CO}_{2}$, and oxidation of $\mathrm{NOx}$ to nitric acid $\left(\mathrm{HNO}_{3}\right)$. In urban areas, the ozone formation process is also accompanied by the conversion of NOx to organic nitrates such as peroxyacetyl nitrate $\left(\mathrm{CH}_{3} \mathrm{CO}_{3} \mathrm{NO}_{2}\right.$, often abbreviated as PAN), which has the effect of transporting NOx to the remote troposphere. In addition to their impact on ozone, NOx and VOC are associated with various other pollutants which impact human health and activities.

However, the effect of $\mathrm{CH}_{4}$ in particular has been identified as a major influence on ambient ozone because increases in $\mathrm{CH}_{4}$ lead to increases in ozone worldwide and thus contribute indirectly to urban and regional pollution events (Fiore et al., 2002a;
West et al., 2006). Shorter lived volatile organics (with lifetimes ranging from 1hour to 3 days) are more important in terms of urban photochemistry because they undergo reactions rapidly enough to contribute to ozone formation during local air pollution events. Alkenes, aromatics, and oxygenated organic species such as formaldehyde (HCHO) are especially important in terms of urban photochemistry because they initiate reaction sequences that generate additional $\mathrm{OH}$ radicals (which catalyze further ozone production) in addition to producing ozone directly.

\subsection{Atmospheric Aerosol Particles Atmospheric}

Aerosol particles are microscopic solid or liquid matter suspended in the atmosphere of Earth.

The term aerosol commonly refers to the particulate/air mixture, as opposed to the particulate matter alone (Seinfeld and Pandis, 1998). Sources of particulate matter can be natural or anthropogenic (Plainiotis et al., 2010). Particulates, or aerosols, have wide-ranging impacts on both human health and environmental quality, in addition to direct inhalation. These effects account for much of the uncertainty in current predictions for future climate (Forster et al., 2007).

\section{EMISSION OF BIOGENICS}

In addition to anthropogenic sources, there are significant biogenic sources of organics. Isoprene $\left(\mathrm{C}_{5} \mathrm{H}_{8}\right)$ is emitted by a variety of deciduous trees (especially oaks), and these emissions have a significant impact on ozone formation. Terpenes (e.g., a-pinene and $\mathrm{C}_{10} \mathrm{H}_{10}$ ) are emitted primarily by conifers and are precursors of particulates. Emission of biogenic VOC often equals or exceeds the rate of emission of anthropogenic VOC at the regional scale, and even within urban areas, biogenic VOC can account for a significant percentage of total VOC reactivity. Biogenic VOC are specifically important due to their relatively short lifetime (1hour or less) 
and consequently contribute to local ozone formation during pollution events.

The major significance of biogenic VOC with regard to ozone lies in their implications for the effectiveness of control strategies and their impact on ozone - Nox - VOC chemistry. The presence of biogenic VOC in polluted regions effectively increases the ratio of VOC to NOx, especially when ratios are weighted by the rate of reactivity. Consequently, regions with biogenic VOC are more likely to have ozone formation that is sensitive to NOx rather than VOC (Chameides et al., 1988; Pierce et al., 1998; Simpson, 1995). Biogenic sources of $\mathrm{NOx}$ are generally too small to contribute significantly to pollution events. Biogenic NOx emissions can be important in intensively farmed regions, where soil emission of NOx is enhanced by heavy use of fertilizer.

\section{ENVIRONMENTAL AND HEALTH IMPACTS}

The consequence of ozone, acid aerosols, and other related pollutants on environment and human health has been the subject of concerns (Dockery et al., 1993; Hoening, 2000; Holgate et al., 1999; Lippman, 2000; Lippman and Schlesinger, 2000; Wilson and Spengler, 1996). It is proved that present ambient levels of both ozone and acid aerosols have pronounced health impacts.

In addition, some studies have discussed that ozone is being linked with both degradation to agricultural crops (Mauzerall and Wang, 2001) and forests (US Congress, 1989). Particulates are responsible for most of the visibility problems associated with air pollution (Seinfeld and Pandis, 1998). The most direct and striking evidence for health effects from air pollution is found in particulates. In United States, a series of studies have shown that mortality rates correlate with exposure to particulates (Dockery et al., 1993; Lippman and Schlesinger, 2000).
Both the primary and secondary pollutants in photochemical smog are highly reactive. These oxidizing compounds have been linked to a variety of negative health outcomes; ozone, for example, is known to irritate the lungs. Smog is a particular health danger in some of the world's sunniest and most populated cities, such as Shanghai in china; the city is typically sunny, and the sun reacts with the chemicals produced by cars and other industrial processes. Hence, most major cities around the globe have problems with smog and air pollution (Lumen, 2019).

\section{OVERVIEW OF OZONE MODELING PHASES}

Ozone modeling involves two (2) major phases, the base case and the future case (with sub steps in each phase). The base case evaluates procedures and ensures that the model is performing correctly. The future case evaluates the effectiveness of controls and demonstrates attainment based on how much ozone will be created in the future. A photochemical grid model simulates the atmosphere above a city by dividing it into thousands of boxes, essentially splitting it into individual grid cells that are typically a few kilometers wide. The thickness of the cells varies as the grid cells that are higher in the atmosphere tend to be thicker than the grid cells closer to the ground. The photochemical model calculates concentrations of pollutants, such as ozone, in each cell by simulating the following four (4) parameters:

i. The movement of air into and out of the grid cells,

ii. The mixture of pollutants vertically among the layers,

iii. The injection of new emissions from sources such as point, area, mobile, biogenic into each grid cell, and 
iv. The chemical reactions based on chemical equations, pollution precursors, and incoming solar radiation in each grid cell.

\section{PHOTOCHEMICAL MODELS}

The two (2) most popular photochemical models mostly used by the air quality modeling community are the Comprehensive Air Quality Model with Extensions (CAMx) and the Community Multiscale Air Quality (CMAQ) Modeling System. These models might experience a rise in popularity in the coming years if the proposal to reduce the ozone primary and secondary standards is finalized as they are multi-scale photochemical modeling system for gas and particulate air pollution.

\subsection{The Comprehensive Air quality Model with extensions (CAMx)}

The Comprehensive Air quality Model with extensions (CAMx) is a state-of-the-science photochemical grid model that comprises a "oneatmosphere" treatment of tropospheric air pollution (ozone, particulates, air toxics) over spatial scales ranging from neighborhoods to continents. It is an open-source system that is computationally efficient, flexible, and available at zero cost. Meteorological inputs are supplied to CAMx from separate weather prediction models (specifically WRF, MM5 and RAMS are supported). Emission inputs are supplied from external pre-processing systems (e.g., SMOKE and EPS3).

\subsubsection{Features of CAMx}

In addition to the features this model shares with other photochemical grid models, the most notable features of CAMx are:

6.1.1.1 Two-Way Nested Grid Structure: This can be simply referred to as flexible two-way grid nesting on many map projections. In this case, CAMx can be run with variable grid spacing. Use a coarse grid for regional domains where high spatial resolution is not particularly needed, while in the same run, nest finer grids in specific areas of interest. Two-way nesting propagates information both up and downscale across all grids. Nests may possess different meshing factors from their parent grids, as long as they are common denominators of parent resolution. A "Flexi-Nesting" feature allows you to introduce and/or remove nested grids at any point during a simulation. You can supply complete information for nested grids (emissions, meteorology, and surface characteristics) or allow CAMx to interpolate any or all of these inputs from parent grids.

\subsubsection{Parallel Processing: CAMx supports two} types of parallelization:

1) Open MP (OMP), which allows parallel processing on shared-memory (e.g., multi-core) computers; and

2) Message Passing Interface (MPI), which allows parallel processing across shared and distributed memory (networked) computer cluster environments.

In order to maximize speed performance, both OMP and MPI can be used in combination. FORTRAN compilers recognize in-code OMP directives. To use MPI, the model must be able to access external MPI libraries installed on the working system.

\subsubsection{Multiple Photochemical Gas Phase} Chemistry Mechanisms: CAMx offers several versions of Carbon Bond chemistry (CB05 and CB6 variants) and the 2007 version of Statewide Air Pollution Research Center chemistry (SAPRC07TC). These mechanisms are solved using the Euler Backward Iterative (EBI) method, which is fast and accurate. CAMx also includes the fully explicit Geartype Livermore Solver for Ordinary Differential Equations (LSODE), which we use to "benchmark" 
new mechanisms and evaluate the performance of EBI. We do not recommend LSODE for typical applications as the model will run much more slowly.

6.1.1.4 Advanced Photolysis Model: This is the Advanced External Photolysis Model (TUV) with in-line cloud and Aerosol Adjustments. The TUV radiative transfer and photolysis model (developed and distributed by the National Center of Atmospheric Research), is used as a CAMx preprocessor to provide the air quality model with a multi-dimensional lookup table of clear-sky photolysis rates. CAMx internally adjusts clear-sky rates for the presence of clouds and aerosols using a fast in-line version of TUV.

\subsubsection{Plume-in-Grid ( $\mathrm{PiG}$ ) Module: $\mathrm{PiG}$ treats the} chemistry and dispersion of point source emission plumes at sub-grid scales using a Lagrangian puff model, until such time as plume concentrations can be adequately represented on the model grid. Both gas-phase and PM chemistry can be treated. PiG includes a "sampling grid" capability to passively sample plume concentrations at any resolution, which allows visualization of near-source sub-grid scale impacts.

\subsubsection{Vertical Diffusion (Mixing) Options: CAMx} offers a standard "K-theory" approach for vertical diffusion or alternatively version 2 of the Asymmetric Convective Model (ACM2; Pleim, 2007). ACM2 is a hybrid of local K-theory diffusion and non-local convective transport between the surface and layers aloft. ACM2 does not work with the Integrated Process Rate (IPR) component of the Process Analysis (PA) tool.

6.1.1.7 Dry Deposition Options: CAMx offers two dry deposition options: an older approach based on the models of Wesely (1989) and an updated approach based on the algorithms of Zhang et al. (2001; 2003). The Wesely model is formulated for 11 landuse categories, while the Zhang model uses 26 landuse categories. Dry deposition, by which substances are ultimately removed from the atmosphere in the absence of precipitations, can be quantitatively important and its parameterisation, both spatially and temporally, appears essential. The "big-leaf model" formulation was used by Michou et al., 2002 which assures that the concentration of a trace gas at the surface is zero, and that the turbulent transport near and into the surface can be accounted for by three in-series resistances, the aerodynamic, quasi-laminar and surface resistances.

\subsubsection{Horizontal Advection Solver Options: CAMx} uses the Piecewise Parabolic Method (PPM) of Colella and Woodward (1984), and the areapreserving advection solver. Both possess high-order accuracy, little numerical diffusion, and are sufficiently quick for applications on very large grids.

\subsubsection{Surface Chemistry/Re-emission Model:} CAMx includes a simple surface sub-model that treats sorption and penetration of deposited pollutant mass into soil, snow and vegetation, chemical degradation and transformation, and volatilization back into the air (re-emission). The surface model treats any subset of species listed in the core model's chemical mechanism, while all chemical rates, sorption and penetration coefficients are user-defined. The surface model cannot be used with the Plume-in-Grid treatment.

\subsubsection{Worldwide Applications of CAMx}

CAMx could be employed in a large scale by local, state, regional, and federal government agencies, academic and research institutions, and private consultants for regulatory assessments and general research throughout the world (Ramboll Environ, 2016). CAMx has been notably found to be 
effectively used in more than 20 countries on nearly every continent as shown in the map below.

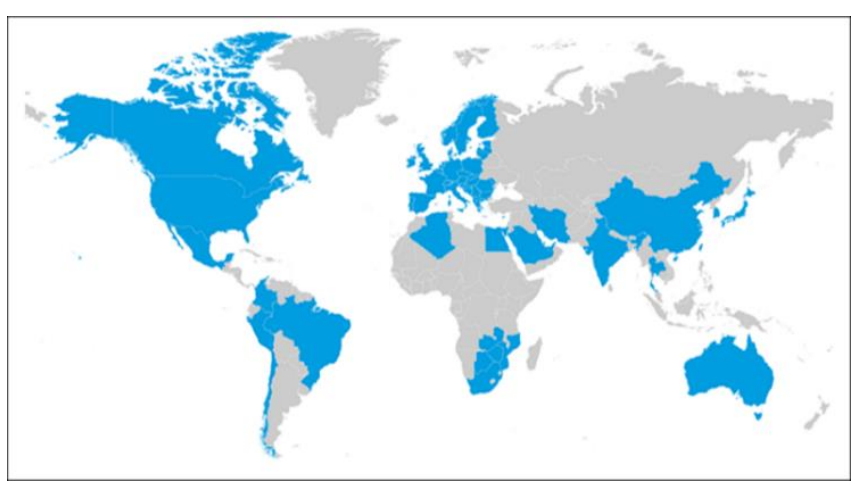

Figure 1: Ramboll Environ, 2016

\subsubsection{Model Formulation}

\subsubsection{Core Model Formulation}

CAMx simulates the emission, dispersion, chemical reaction, and removal of pollutants by marching the Eulerian continuity equation forward in time $(t)$ for each chemical species (l) on a system of nested three-dimensional grids. The continuity equation specifically describes the time dependency of volume-average species concentration within each grid cell as a sum of all physical and chemical processes operating on that volume. This equation is expressed mathematically in terrain-following height ( $\mathrm{z})$ coordinates as follows:

$$
\begin{aligned}
\frac{\partial c_{l}}{\partial t}= & -\nabla_{H} \cdot V_{H} c_{l}+\left[\frac{\partial\left(c_{l} \eta\right)}{\partial z}-c_{l} \frac{\partial^{2} h}{\partial z \partial t}\right]+\nabla \cdot \rho K \nabla\left(c_{l} / \rho\right) \\
& +\left.\frac{\partial c_{l}}{\partial t}\right|_{\text {Emission }}+\left.\frac{\partial c_{l}}{\partial t}\right|_{\text {Chemistry }}+\left.\frac{\partial c_{l}}{\partial t}\right|_{\text {Removal }}
\end{aligned}
$$

\subsubsection{The Zhang Model formulation}

Environment Canada's AURAMS air quality model uses a state-of-the-science deposition scheme that possesses an updated representation of non-stomatal deposition pathways (Zhang et al. 2003). The approach incorporates the "leaf area index" (LAI), which is an important aspect of newer dry deposition schemes that allows for scaling of pollutant uptake into biota of varying densities. LAI is defined as the ratio of the one-sided green leaf area to a unit area of the ground. It is measured by satellite instruments at fairly high spatial resolution. The Zhang model has been tested extensively through its use in daily air quality forecasting in Canada, and has been shown to reproduce observed fluxes of ozone and SO2 with reasonable accuracy. In CAMx, the Zhang model has tended to generate lower ozone deposition rates relative to the Wesely model, which leads to higher ozone predictions overall. This effect is seasonally dependent and will vary with the definition of LAI. Ozone is less sensitive to the source of LAI (whether Zhang defaults or satellite-enhanced) than to the choice of deposition model.

\subsection{Dry Deposition of Gases}

The gas resistance model of Zhang et al. (2003) invokes the same 3-resistance equation for deposition velocity as the Wesely (1989) model. The equations for aerodynamic resistance $\left(r_{a}\right)$ and boundary resistance $(r b)$ are very similar to the Wesely (1989) formulations. However, Zhang et al. (2003) replace the surface resistance $\left(r_{s}\right)$ equation with a new relationship for the overall canopy resistance:

$$
r_{c}=\frac{1}{\frac{1-W_{s t}}{r_{s t}+r_{m}}+\frac{1}{r_{c u t}}+\frac{1}{r_{a c}+r_{g s}}}
$$

Where $W_{\text {st }}$ is the fraction of stomatal blocking under wet conditions, ${ }^{\mathrm{r}}$ cut is the cuticle resistance, and all other resistances have similar meaning to the Wesely model. Stomatal resistance $\left(r_{s t}\right)$ is calculated using a sunlit/shade (so-called "two-big-leaf") stomatal resistance sub-model. 
Following Wesely (1989), values for $r_{g}$ and $r_{c u t}$ are calculated for $\mathrm{SO}_{2}$ and $\mathrm{O}_{3}$ and then scaled for other gaseous species. Cuticle resistance is slightly different from that defined in traditional big-leaf models in that it also considers the aerodynamic and quasi-laminar resistances of individual leaves. This is done by parameterizing $r_{c u t}$ as a function of friction velocity, similar to the concept of overall cuticle uptake considered in a multi-layer model framework

LAI is used in functions for $r_{a c}$, and $r_{c u t}$, where the LAI for any given day is linearly interpolated from monthly default LAI as a function of landuse type. To account for LAI effects on surface roughness (z0), a similar daily LAI interpolation is applied to that parameter. Hence, the Zhang model does not require the specification of season, as all resistance equations are continuous over each month (note that CAMx automatically applies the 6-month offset for applications in the southern hemisphere).

For snow on the ground and leaves, both $r_{g s}$ and $r_{c u t}$ are adjusted by a snow cover fraction, which is calculated from snow depth, snow age, and landuse type. Snow cover is defined through the input 2D surface file. For surfaces without canopies, $r_{g s}$ is defined as the resistance to any surface (e.g. soil, ice, snow and water), $r_{a c}$ is set to zero, and very large values are used for $r_{s t}, r_{m}$ and $r_{c u t}$.

Over water, the updated temperature-dependent ozone surface resistance equation described above for the Wesely scheme is also used for the Zhang scheme.

The Zhang model includes a set of embedded annual surface roughness ranges and monthly LAI specific to each of the 26 landuse categories. The capabilities of the scheme were extended by adding the option to use episode-specific (i.e. satellite-derived) LAI data. Satellite-based LAI data from MODIS2
(MODerate-resolution Imaging Spectroradiometer) can be processed into gridded LAI fields that are passed to CAMx as an optional record in the timeinvariant 2D surface input file. The optional gridded LAI fields are used to scale the default landusespecific LAI values. For each grid cell, a landuseweighted default LAI is determined according to the landuse fractions present. An LAI scaling factor is then determined as the ratio of the input LAI to the landuse-weighted default LAI. This factor is used to scale the individual default LAI values for each landuse type in the grid cell, subject to the annual maximum to minimum range among the monthly default values. Figure 2 illustrates how the use of satellite LAI data introduces additional episodespecific variation into the LAI field.

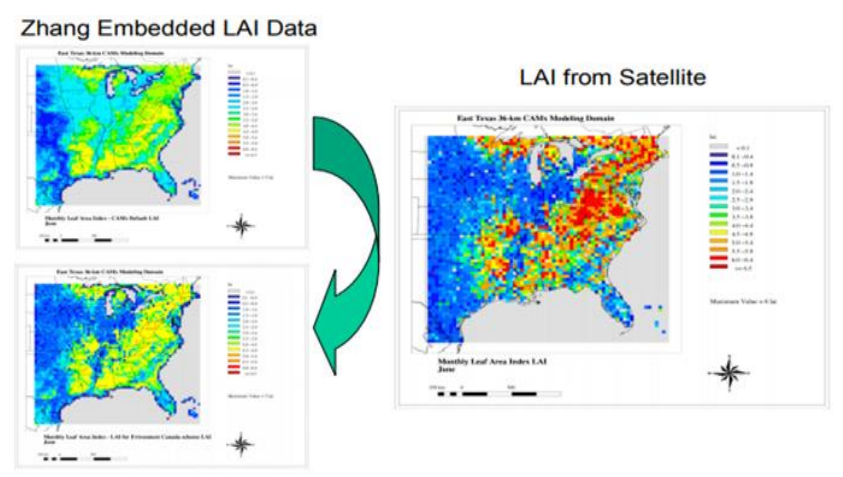

Figure 2: Comparison of monthly LAI data embedded in the Zhang dry deposition scheme against episode-specific LAI for June 2005.

\subsection{The Community Multiscale Air Quality (CMAQ) Model}

CMAQ is an active open-source development project of the U.S. Environmental Protection Agency (EPA) that consists of a suite of programs for conducting air quality model simulations. CMAQ is supported and distributed by the CMAS Center. The Community Multiscale Air Quality (CMAQ) model is a numerical air quality model that relies on scientific principles to predict the concentration of airborne gases and particles, and the deposition of these pollutants back to Earth's surface. Because it 
includes information about the emissions and properties of compounds and classes of compounds, CMAQ can also inform users about the chemical composition of a mixture of pollutants. This is particularly useful when measurements only give insight into aggregate details, like total particulate mass (EPA, 2019).
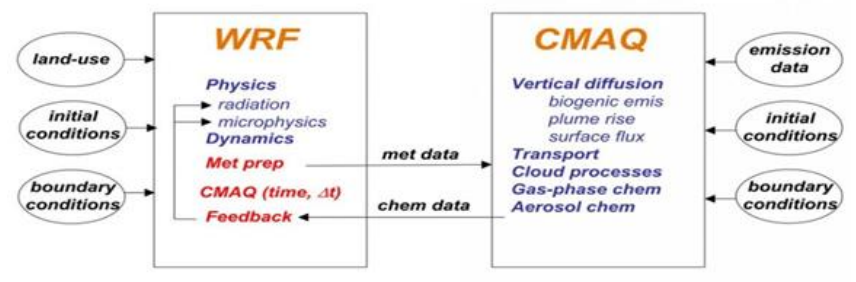

The purpose of CMAQ is to provide fast, technically sound estimates of ozone, particulates, toxics, and acid deposition. CMAQ is designed to meet the needs of the scientific community and concerned community leaders by combining current knowledge in atmospheric science and air quality modeling, multi-processor computing techniques, and an open-source framework into a single modeling system.

\subsubsection{Applications of the CMAQ Model}

CMAQ is applied to explore different kinds of air pollution scenarios. For instance, CMAQ is often used to test the impact of future emission regulations. The interaction of meteorology and air quality, e.g. the effects of particles on solar radiation, can be explored with the two-way WRF-CMAQ system, which couples the Weather Research and Forecasting (WRF) meteorological model with the CMAQ air quality model. The Direct-Decoupled Method (DDM) can be used in CMAQ-DDM to quantify the sensitivity of air pollution predictions to model input values like emissions or reaction rates. Often, people want know more about which individual emission source or group of sources are contributing the most to the air pollution at a site. This can be explored using the Integrated Source-
Apportionment Method (ISAM) in the CMAQISAM model (EPA, 2019).

\subsubsection{CMAQ History}

Since 1998, when the first version was released, CMAQ has been used to evaluate potential air quality policy management decisions. The model provides reliable information for decision makers about the estimated impacts of different air quality policies. CMAQ's generalized and flexible formulation has enabled incorporation of alternate process algorithms and numerical solution methods. This has allowed inclusion of new science in the model to address increasingly complex air pollution issues (EPA, 2019).

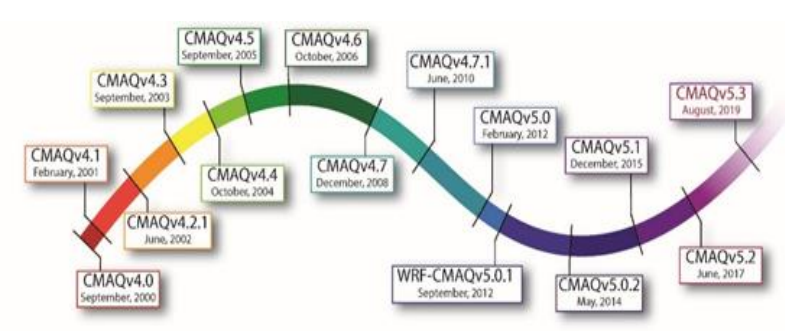

Figure 3: EPA (2019): Community Multiscale Air Quality Modeling System (CMAQ) retrieved on 2/9/2019 available at https://www.epa.gov/cmaq/cmaq-models-0

\section{ACKNOWLEDGEMENT}

The work is supported by the United Nations International Students' Conference on Environment and Sustainability, 2019.

\section{REFERENCES}

[1]. Carter, W. P. L., Winer, A. M. and Pitts, J. N., Jr. (1982a); Effect of kinetic mechanisms and hydrocarbon composition on oxidantprecursor relationships predicted by the EKMA isopleth technique. Atmospheric Environment 16, 113-120.

[2]. Carter, W. P. L., Atkinson, R., Winer, A. M., and Pitts, J. N., Jr. (1982b); Experimental investigation of chamber-dependent radical sources. Int. J. Chem. Kinet. 14, 1071-1103. 
[3]. Chameides, W. L, Lindsay, R. W, Richardson, J., and Kiang, C. S (1988); The role of biogenic hydrocarbons in urban photochemical smog: Atlanta as a case study. Science 241: 14731474.

[4]. Chatfield, R. B, Vastano, J. A, Li, L., Sachse, G. W., and Conners, V. S. (1998); The Great African plume from biomass burning: Generalizations from a three-dimensional study of TRACE A carbon monoxide. Journal of Geophysical Research 103: 28059-28078.

[5]. Colella, P. and Woodward, P. (1984) Journal of Computer and Physics. 54, 174. Mathematic Science Net ADSzb MATH

[6]. Dunker, A. M., Kumar, S. and Berzins, P. H. (1984); A comparison of chemical mechanisms used in atmospheric models. Atmospheric Environment 18, 31 1-321.

[7]. Dockery, D. W, Pope, C. A, Xu, X. et al., (1993); An association between air pollution and mortality in six U.S. cities. New England Journal of Medicine 329: 1753-1759.

[8]. Dodge MC (2000); Chemical oxidant mechanisms for air quality modeling: Critical review. Atmospheric Environment 34: 21032130.

[9]. EPA (2019); Community Multiscale Air Quality Modeling System (CMAQ) retrieved on $2 / 9 / 2019$ available at https://www.epa.gov/cmaq/cmaq-models-0

[10]. Eschenroeder, A. Q. and Martinez, J. R. (1971); concept and applications of photochemical smog models; General Research Corporation, Santa Barbara, California 93105

[11]. Fiore, A. M, Jacob, D. J, Bey, I., et al., (2002a); Background ozone over the United States in summer: Origin, trend, and contribution to pollution episodes. Journal of Geophysical Research 107(D15): 4275.
[12]. Fiore, A. M, Jacob, D. J, Field, B. D, Streets, D. G, Fernandes, S. D, and Jang, C. (2002b); Linking ozone pollution and climate change: The case for controlling methane. Geophysical Research Letters 29(19): 1919.

[13]. Fiore, A. M, Jacob, D. J, Logan, J. A, and Yin, J. $H$ (1998); Long-term trends in ground level ozone over the contiguous United States, 1980-1995. Journal of Geophysical Research 103: 1471-1480.

[14]. Fiore, A. M, Dentener, F. J, Wild, O., et al., (2009); Multi - model estimates of intercontinental source-receptor relationships for ozone pollution. Journal of Geophysical Research 114: D04301.

[15]. Forster, P., Ramaswamy, V., Artaxo, P., et al., (2007); Changes in atmospheric constituents and in radiative forcing. In: Solomon S, Qin D, and Manning M, et al. (eds.) Climate Change 2007: The Physical Science Basis. Contribution of Working Group I to the Fourth Assessment Report of the Intergovernmental Panel on Climate Change; Cambridge/New York: Cambridge University Press.

[16]. Hoening, J. Q (2000); Health Effects of Ambient Air Pollution: How Safe Is the Air We Breathe? Norwell/Dordrecht: Kluwer Academic Publishers.

[17]. Holgate, S. T, Samet, J. M, Koren, H. S, and Maynard, R. L. (eds.) (1999); Air Pollution and Health. London/San Diego: Academic Press.

[18]. Jeffries, H. E., Sexton, K. G. and Salmi, C. N. (1981); Effects of chemistry and meteorology on ozone control calculations using simple trajectory models and the EKMA procedure. Final Report to the U.S. Environmental Protection Agency under contract No. 68-023523, School of Public Health, University of North Carolina, Chapel Hill, North Carolina.

[19]. Leone, J. A. and Seinfeld, J. H. (1984); comparative analysis of chemical Reaction 
Mechanisms for phytochemical smog; California institute of technology, Pasadena.

[20]. Lippman, M. (ed.) (2000); Environmental Toxicants: Human Exposures and Their Health Effects. New York: Wiley-Interscience.

[21]. Lippman, M. and Schlesinger, R. B. (2000); Toxicological bases for the setting of healthrelated air pollution standards. Annual Review of Public Health 21: 309-333.

[22]. Lumen (2019); chemistry and the real world retrieved on 25/08/2019 from https://courses.lumenlearning.com/introchem/ chapter/photochemical-smog/

[23]. Mauzerall, D. L., Narita, D., Akimoto, H. et al., (2000); Seasonal characteristics of tropospheric ozone production and mixing ratios over east Asia: A global three dimensional chemical transport model analysis. Journal of Geophysical Research 105: 17895-17910.

[24]. Mauzerall, D. L. and Wang, X. (2001); Protecting agricultural crops from the effects of tropospheric ozone exposure: Reconciling science and standard setting in the United States, Europe, and Asia. Annual Review of Energy and the Environment 2001(26): 237268

[25]. Michou M., Brocheton F., Dufour A., Peuch VH. (2002) Surface Exchanges in the Multiscale Chemistry and Transport Model MOCAGE. In: Sportisse B. (eds) Air Pollution Modelling and Simulation. Springer, Berlin, Heidelberg

[26]. Mohan, S. Mariraj (2016) An overview of particulate dry deposition: measuring methods, deposition velocity and controlling factors; International Journal of Environmental Scienec Technology. 13:387 402, DOI 10.1007/s13762-015-0898-7

[27]. Parrish, D. D, Dunlea, E. J, Atlas, E. L, et al., (2004); Changes in the photochemical environment of the temperate North Pacific troposphere in response to increased Asian emissions. Journal of Geophysical Research 109: D23S18.

[28]. Pierce, T., Geron, C., Bender, L., Dennis, R., Tonnesen, G., and Guenther, A. (1998); Influence of increased isoprene emissions on regional ozone modeling. Journal of Geophysical Research 103: 25611-25630.

[29]. Plainiotis, S.; Pericleous, K.A.; Fisher, B.E.A.; Shier, L. (January 2010). "Application of Lagrangian particle dispersion models to air quality assessment in the Trans-Manche region of Nord-Pas-de-Calais (France) and Kent (Great Britain)". International Journal of Environment and Pollution (IJEM). 40 (1/2/3): 160-174. doi:10.1504/IJEP.2010.030891]

[30]. Pleim JE (2007) A combined local and nonlocal closure model for the atmospheric boundary layer, part I: model description and testing. Journal of Applied Meteorology and Climatology 46:1383 - 1395

[31]. Ramboll Environ (2016); CAMx Applications Worldwide Retrieved on 3/9/2019, available at http://www.camx.com/about/us-camxapplications.aspx

[32]. Seinfeld, J. H. and Pandis, S. (1998). Atmospheric Chemistry and Physics: From Air Pollution to Climate Change (2nd ed.). Hoboken, New Jersey: John Wiley \& Sons. p. 97. ISBN 978-0-471-17816-3.

[33]. Shawn J. Rossele, Jonathan E. Pleim, and Kenneth, L. Schere (1997); development and testing of an improved photolysis rate model for regional photochemical modelling; presentation at the air and waste management association's 90th annual meeting and exhibition, Toronto, Ontario, Canada. 97 RP94B.01

[34]. Sillman, S., Vautard, R., Menut, L., and Kley, D. (2003); O3-NOx-VOC sensitivity and NOxVOC indicators in Paris: Results from models 
and Atmospheric Pollution over the Paris Area ESQUIF measurements; Journal of Geophysical Research.

[35]. Sillman, S. and Arbor, A. (2014); Tropospheric Ozone and Photochemical Smog; university press, university of Michigan.

[36]. Simpson, D. (1995); Biogenic emissions in Europe 2; Implications for ozone control strategies. Journal of Geophysical Research 100: 22891-22906

[37]. US Congress (1989); Catching Our Breath: Next Steps for Reducing Urban Ozone. Office of Technology Assessment OTA-O-412. Washington, DC: US Government Printing Office.

[38]. Wesely (1989) Wesely, M.L., Parameterization of surface resistances to gaseous dry deposition in regional-scale numerical models, Atmospheric Environment, 23, 6, 1293 - 1304, 1989.

[39]. West, J. J, Fiore, A. F, Horowitz, L. W, and Mauzerall, D. L. (2006); Global health benefits of mitigating ozone pollution with methane emission controls. Proceedings of the National Academy of Sciences of the United States of America 103(11): 3988 - 3993.

[40]. Whitten, G. Z. (1981); Comments at U.S. Environmental Protection Agency Workshop on the Empirical Kinetic Modeling Approach, 15-16 December, Research Triangle Park, N.C.

[41]. Wilson, R. and Spengler, J. D. (eds.) (1996) Particles in Our Air: Concentrations and Health Effects. Cambridge, MA: Harvard School of Public Health, Harvard University Press.

[42]. Wilson, W. E. and Suh, H. H. (1997); Fine particles and coarse particles: Concentration relationships relevant to epidemiologic studies. Journal of the Air and Waste Management Association 47: 1238-1249.

[43]. Zhang L, Vet R (2006) A review of current knowledge concerning size-dependent aerosol removal. China Particuol 4(6):272 - 282

[44]. Zhang L, Gong S, Padro J, Barrie L (2001) A size-segregated particle dry deposition scheme for an atmospheric aerosol module. Atmospheric Environ 35:549-560

[45]. Zhang L, Fang GC, Liu CK, Huang YL, Huang JH, Huang CS (2012) Dry deposition fluxes and deposition velocities of seven trace metal species at five sites in Central Taiwan - a summary of surrogate surface measurements and a comparison with model estimation. Atmospheric Chemistry Phys 12:3405 - 3417

[46]. Zhang Zhihua \& Chibiao Chen \& Jian Sun \& Kap Luk Chan (2003): "EM algorithms for Gaussian mixtures with split-and-merge operation." Pattern Recognition 36: 1973 1983

[47]. Zheng M, Guo Z, Fang M, Rahn KA, Kester DR (2005) Dry and wet deposition of elements in Hong Kong. Mar Chemical 97:124 - 139

\section{Cite this article as:}

Muhammad Ibrahim, "Air Quality Analyses for Photochemical Smog Associated with Atmospheric Aerosol Particles and Ozone Precursors Using CMAQ and CAMx Modeling Systems", International Journal of Scientific Research in Science and Technology (IJSRST), Online ISSN: 2395-602X, Print ISSN: 2395-6011, Volume 6 Issue 5, pp. 224-235, September-October 2019. Available at doi: https://doi.org/10.32628/IJSRST196530 Journal URL: http://ijsrst.com/IJSRST196530 